\title{
Bad Mothers and Strange Offspring: Images of Scrubfowl and Sea Turtles in Eastern Indonesia
}

\author{
Gregory Forth ${ }^{1}$ \\ ${ }^{1}$ Department of Anthropology, University of Alberta, Edmonton, Canada. \\ *'gforth@ualberta.ca
}

\begin{abstract}
One way birds communicate knowledge to humans and facilitate communication among humans is through metaphors. A recent book discusses animal metaphors, nearly a third of which employ birds as vehicles, used by the Nage people of Flores Island (eastern Indonesia). As applied to human beings and human behaviors, bird metaphors reveal considerable overlap with other animal metaphors; thus, a full understanding of these requires additional attention to the metaphoric or more generally symbolic value of other sorts of non-human animals. Emphasizing how knowledge of birds is shaped in some degree by an extra-cultural empirical experience of the creatures, the present discussion explores similar representations of a bird, the scrubfowl, and a marine reptile, the sea turtle, among people in several parts of Flores.
\end{abstract}

Received July 12, 2019

OPEN ठACCESS

Accepted October 28, 2019

Published December 4, 2020

DOI 10.14237/ebl.11.2.2020.1624

Keywords Animal metaphor, Moral symbolism, Scrubfowl, Sea turtles, Flores Island, Indonesia

Copyright (C) 2020 by the author(s) licensee Society of Ethnobiology. This is an open-access article distributed under the terms of the Creative Commons Attribution-NonCommercial 4.0 International Public License (https://creativecommons.org/licenses/by-nc/4.0), which permits non-commercial use, distribution, and reproduction in any medium, provided the original author and source are credited.

Birds can communicate to humans, other birds, and to a variety of other creatures in their own voices. However, birds also communicate-to humans particularly-through metaphor: by way of their physical forms, activities, and indeed through their songs and cries, providing humans with ways of talking about a variety of topics, but especially other people. In a recent book (Forth 2019a) I explore 566 animal metaphors employed by the Nage people of Flores Island in eastern Indonesia. Nearly 180 of these incorporate 49 categories of birds, all of which are folk-generics corresponding to English terms like "crow," "eagle," and "kingfisher." One finding of the book is that the large majority of Nage bird metaphors, like animal metaphors in general, refer to human beings, and that many of these serve to convey moral ideas about proper and improper conduct. Another finding is that synonymous or at least very similar metaphors can have very different kinds of animals as their vehicles-for example, a bird and a mammal or a bird and a reptile. The present discussion centers largely on Florenese ideas concerning a bird, the scrubfowl, and a marine reptile, the sea turtle, and my aim is to show how-by virtue of their similar reproductive behaviors-both creatures participate in a similar moral symbolism.

Found throughout Flores Island, the scrubfowl (specifically the Orange-footed scrubfowl, Megapodius reinwardt) is a Megapode, which, true to its name, has big feet. In all other respects, and in regard to both size and bodily form, this largely ground-dwelling bird resembles a chicken. Its most peculiar feature in the eyes of Flores islanders is that it is an incubator. That is to say, it lays its eggs - and very big eggs at thatbeneath huge mounds of earth, sand, and leaf litter that reach up to 4.5 meters in height and over 9 meters in diameter (Jones et al. 1995:225), where it leaves the eggs to incubate. As a result, the young birds hatch without any attention from the mother bird. For this reason, Nage describe scrubfowl as "laying eggs (but) not knowing how to sit on them" (telo be'o neke kéwo), or in another interpretation, "laying eggs on the ground, (but) brooding on a tree branch" (telo zale one awu, neke nama da'a kaju). This last specification reflects the local observation that, whenever the scrubfowls are seen-or, more often, heard-the birds are nearly always found in a tree. 
These characteristics, all of which are empirically grounded, contribute to an image of scrubfowl hens as bad mothers who do not take sufficient care of their offspring. In accordance with the large size of the eggs (on Flores weighing up to 140 grams, Jones et al. 1995:226), and therefore the size of the chicks when they hatch, Flores villagers say that newborn scrubfowl are large and strong enough to search for their own food. The observation is ornithologically well founded and, though I never heard Flores Islanders mention it specifically, newborn chicks are sufficiently mature to fly within hours of hatching (Jones et al. 1995:8, 22; Simpson and Day 1993:311).

Both in Nage and in the Keo region, immediately to the south of Nage, people claimed that, to ensure their independence, the mother birds will chase and peck at newborn chicks, and Keo informants further asserted that, in the same context, parent birds will sometimes kill their young. Although this last idea appears empirically less likely, it should be seen in relation to a practice of filial infanticide that is surprisingly widespread among a variety of animal species, including many birds. In fact, scrubfowl are better parents than Flores people perhaps realize, for usually the males "manage the [nest] mound and control the incubating temperature" (Simpson and Day 1993:311), something they achieve "by digging a number of holes and testing the conditions" (Leseberg and Campbell 2015:97). But even if Florenese are aware of this behavior (and I have no evidence that they are), they do not characterize scrubfowl males as caring fathers. In addition, several pairs sometimes use the same mound (MacKinnon 1991; Wallace 1922:120), another practice of scrubfowls that contrasts with the normal nesting behavior of other birds.

Whatever the truth is of scrubfowl parents attacking their young, all locally recognized behaviors of the bird motivate a Nage metaphor referring to women who give birth and then desert or inadequately provide for their offspring. Such women are thus described as "like scrubfowl that lay their eggs and just leave them" (bbia koko wodo telo ea telo ea). Although observable attributes of the birds would appear to sufficiently account for Nage selection of the scrubfowl for this metaphorical role, a certain irony (thus another device of verbal symbolism) is also discernible in the usage. In shape, size, and largely ground-dwelling habit, and its "loud crowing and cackling calls" (Leseberg and Campbell 2015:96), the bird closely resembles a chicken. Yet in contrast to the scrubfowl, domestic hens are represented, particularly in Nage metaphor, as the most maternal of birds.

At this point a linguistic note is useful. The Nage name for the scrubfowl, koko wodo, comprises two parts. The first is koko, an onomatope which replicates the bird's cries and is almost identical to another onomatope, kako, "to crow (of a domestic cock)." The second, wodo, is the sole name for the bird in several Florenese languages, as are cognates in other east Indonesian languages, and appears to reflect a Central-Malayo-Polynesian proto-term (Forth 2010:238). In Nage, wodo further refers to the practice of domestic hens sheltering chicks beneath their wings, a common behavior serving to protect their offspring. Although this second meaning may reflect a different protoform, the two senses are nevertheless covered by a single Nage word, and in view of their perception of female scrubfowl as bad mothers, it is likely that the irony is not lost on Nage and that the birds' overall resemblance to chickens further motivates the metaphor.

Apart from the metaphor, there is another symbolic usage, an obviously fantastic local idea concerning scrubfowl that is similarly connected with the birds' seemingly poor maternal habits and the absence of any evident relationship between mother bird and offspring that becomes apparent from the very moment eggs are laid. On Flores, the Orangefooted scrubfowl is now considered rare and people describe its numbers as much reduced from perhaps a half century ago, when the birds and their nest mounds were more regularly encountered, and the mounds were exploited for their eggs. Even so, people still recognize the birds as occurring both in highland areas and near the coast, where they appear to be more common. Nage and other Flores Islanders further claim that when scrubfowl nest relatively close to the sea some of their eggs will hatch into sea creatures, while others hatch into scrubfowl and other land creatures depending on the direction in which the newborns emerge from the egg. According to one variant, scrubfowl chicks that hatch facing the sea will be sea creatures while those that face towards the land will be scrubfowl. Offspring that take a form other than scrubfowl are the strange offspring to which I refer in my title. "Strange" because they are alien in relation to their parents, belonging, according to Nage 
animal taxonomy, not only to other folk-generics but also to other life-forms (sensu Berlin 1992).

Since snakes and similar creatures are among the animals said to emerge from scrubfowl eggs, some basis for the notion that other animals can hatch from these may be found in the actual occurrence of such creatures in or near scrubfowl nest mounds. In fact, snakes and monitor lizards-including Komodo monitors or Komodo dragons Varanus komodoensis (Lincoln 1974), found on Flores as well as on Komodo and small neighboring islands-are among the animals most likely to prey on scrubfowl eggs. However, another source of this idea may be local knowledge and similar beliefs concerning the nesting and parenting habits of another animal, indeed another reptile-the sea turtle.

Two species of sea turtle, the Hawksbill turtle (Eretmochelys imbricata [formerly Chelonia imbricata]) and the Green turtle (Chelonia midas), occur in the waters around Flores. Both are exclusively marine creatures with flippers instead of legs and therefore move awkwardly on dry land. In fact, the only time sea turtles venture on land is when females leave the sea to lay their eggs in holes they dig in sandy beaches, which they afterwards cover with sand before promptly returning to the sea. Exactly like scrubfowl, therefore, turtles are incubators. After laying, they neither brood their eggs, nor do the females attend to newly hatched young which, in the case of sea turtles, will immediately scurry to the sea. In east central Flores, Lio people mention how turtles are peculiar in this respect, since unlike all other marine creatures they live in the sea but lay their eggs on dry land. (Frogs too might be considered similarly inconsistent, because as is generally known, they lay their eggs in water. Adult frogs also spend much time in water, although they are equally at home on dry land.)

Flores Islanders themselves are aware of the similar reproductive behavior of turtles and scrubfowl. But they add one more similarity when they claim that the eggs of turtles also do not hatch only young turtles. According to one version of the belief, it is only when a female turtle, after laying, returns to the sea and rests on the ocean floor facing out to sea that her young are eventually born as turtles (in one view, turtles and fish). On the other hand, if she faces in the opposite direction, that is, towards the land, her eggs will produce a variety of land creatures. Unfortunately, I did not think to ask whether marine turtles might be among the animals that emerge from scrubfowl eggs when the newly hatched turn towards the sea. However, a man in the Sikka region, in the eastern part of Flores - and thus well to the east of Nage and $\mathrm{Keo}$-included scrubfowl (rata wodon) among the land creatures that can emerge from turtle eggs.

Both turtles and scrubfowl - the eggs of which the females do not brood or protect by sitting on their clutches-are thus thought to produce offspring belonging to what islanders consider different lifeforms. It is as though the attendance of the mother animal is required throughout the period of gestation to ensure that all infants will be of the same folkzoological kind. Regarding sea turtles especially, similar ideas are found on various Indonesian islands. On Flores, land creatures that can hatch from turtles' eggs include not only snakes, monitor lizards, skinks, and rats, but also birds. The Sikkanese notion that young scrubfowl can emerge from turtle's eggs has already been noted. Mentioned far more often than scrubfowl are birds that consume ripening crops, such as crows, quails, and Munias (small finches that feed on grain). But the most commonly mentioned of all are cockatoos and parrots, birds which, together with crows, are notorious for ravaging fields of maize.

Why oviparous reptiles of other kinds might hatch from turtle eggs may seem relatively straightforward, but the birds require more attention. Various Flores people describe hawksbill turtles as having heads and mouths or snouts that are shaped like birds' beaks - a resemblance enshrined, of course, in the species' English name. More specifically, they say turtles have heads like cockatoos, a similarity reinforced for speakers of some Flores languages by the fact that words for "turtle" and "cockatoo", though evidently deriving from different protoforms, are similar or identical. The identity of names is taken furthest in dialects of Nage from which the /r/ has disappeared, leaving kea as the word synonymously denoting both marine turtles (elsewhere in languages of the Ngadha-Lio group named kéra) and the cockatoo, which throughout Flores is the Yellowcrested cockatoo (Cacatua sulpurea). When necessary, Nage can distinguish turtles as kea mesi, "sea kea," or as this is occasionally understood "sea cockatoo"; and cockatoos in central Nage can be specified as kaka kéa, a name in some contexts reduced to kaka. Nevertheless, the similarity remains, and Nage themselves understand the partly identical names as reflecting the physical resemblance between turtles 
and birds, and more specifically the resemblance of a turtle's head to that of a cockatoo (Forth 2016:224225). The precedence of cockatoos over turtles in this last formulation-the fact that turtles are compared to cockatoos rather than the other way roundreflects Nage familiarity with cockatoos, birds seen often until they disappeared from many places two or three decades ago. By contrast, as inlanders or highlanders, Nage rarely see marine turtles.

Clearly, the notion that young cockatoos and parrots can emerge from turtle eggs has a basis in the resemblance between the heads of the marine reptiles and the heads of psittacine birds. The idea that other avian crop pests and even rats can also hatch from the eggs might then be attributed to metonymy. That is, cockatoos and parrots, owing to their physical resemblance to turtles, are selected as the part that represents the whole, in this instance a utilitarian category comprising all creatures that do damage to crops. Also, of note is a local notion encountered in several parts of Flores, that pestilence of all sorts (including plague rats as well as birds) ultimately derives from the sea, so that the antidote must also come from the sea- a principle that finds expression in garden magic.

However, this still leaves the question of snakes, monitor lizards, and skinks. As hinted earlier, the association with marine turtles might be traced to these reptiles being, like turtles, mostly oviparous. At the same time, monitors and snakes are great eggeaters, so the association could further be linked to the actual presence of these animals near sea turtle clutches. As mentioned before, snakes and lizards are among creatures Florenese say emerge from scrubfowl eggs, and this idea too can be explained by the presence of these reptiles near scrubfowl nests. Yet as this similarity should suggest, a more general explanation for creatures other than turtles hatching from turtle eggs and creatures other than scrubfowl chicks hatching from scrubfowl eggs lies in what Flores Islanders perceive as the poor parenting skills of both animals. In other words, the common theme is female animals, after laying, not sitting on their eggs and moreover giving no apparent care to their young after they are hatched, thus resulting in not all of their eggs producing young of the proper kind. It should also be recalled that young of the wrong kind are believed to hatch either when the mother animal faces in the wrong direction (toward the land for female sea turtles) or when an egg is inappropriately disposed.
This incorrect orientation, as it were, adds to the perverse character of the adult creatures. In the case of marine turtles, the incorrect orientation recalls the representation of these reptiles as creatures that live entirely in the sea and yet, perversely in the local view, lay their eggs on land.

As I have demonstrated elsewhere (Forth 2017, 2019b), in the Lio region especially, breaches of a major cosmological principle in which things of the land should be kept separate from the sea illuminate a number of local ideas and attitudes towards animals, including beliefs that associate them with spirits. Despite their unusual reproductive behaviors neither marine turtles nor scrubfowl are, as far as I have been able to discover, identified with spirits (for example, earth spirits or sea spirits) in any part of Flores. Nor do the turtles serve as the vehicle for any metaphor motivated by the creatures' egg-laying and parenting practices, or at least none that applies to humansunlike scrubfowls, which provide the Nage with a metaphor for bad motherhood. However, the symbolic value of the sea turtle's peculiar parenting finds a definite expression in agricultural ritual, and in this context, one encounters another kind of verbal metaphor. Bound up with their connection with cockatoos and parrots, and more specifically the belief that sea turtle eggs can give rise both to these birds and to other similarly pestilential creatures, the rites in question, mostly of a magical nature, are performed to lend protection to ripening crops. Thus, in the Lio region, after planting, people burn turtle shell inside a field to keep cockatoos, parrots, and pests of all sorts away. Alternatively, they will bury turtle eggs, one each in the four corners of a field and in the center. These magical acts have a verbal component as well, for in accompanying ritual speech, Lio cultivators do not refer to parrots and cockatoos by their ordinary names (in Lio dialects wékea for cockatoos and tori for parrots [mostly the Great-billed parrot Tanygnathus megalorbynchos]). Rather, they refer to these birds as turtles (kéra), a metaphor that not only alludes to the belief in pestilential animals deriving from turtle eggs, but possibly also suggests that the birds and other creatures are still, in some essential sense, turtles.

\section{Discussion and Conclusions}

The case of scrubfowls and sea turtles provides yet another illustration of how creatures quite unconnected in folk zoological taxonomy can be closely associated by virtue of their symbolic values. Of course, symbolically as well, scrubfowls and turtles 
are by no means completely identical. As seemingly bad parents, only turtles are believed to produce pestilential animals, especially in the shape of psittacine birds linked metonymically with all plague animals. This association is largely explained by an explicit physical resemblance between turtles and cockatoos and parrots. In contrast, scrubfowls have no such negative significance; the strange hatchlings believed to emerge from some of their eggs do not damage cultivated fields, nor do they negatively affect any human endeavor, and evidently as a result the scrubfowl plays no part in ritual. In addition, in Flores garden-magic turtles provide their own antidote to the crop depredations they ultimately cause by way of their strange offspring, in the form of fragments of their shells or their eggs- a straightforward case of magical homeopathy. Yet scrubfowls arguably do something similar. Not only does the scrubfowl provide an identical model of bad parenthood, but like turtles they might be seen as making up for this by providing an antidote in the form of a metaphor, which in effect warns people against going the way of this peculiar bird.

I close with remarks on animal transformation. Partly because the idea of scrubfowl eggs hatching creatures of quite different species appears to be less well or widely known on Flores, it is possible that the belief is derivative of an older and possibly more widespread belief concerning turtles. However that may be, as applied to either species, the notion of creatures laying eggs from which different kinds of animals can emerge suggests a comparison with what I have elsewhere called "transformation beliefs" (Forth 2016). By this phrase I refer to the idea that certain animals, at some stage in their lives and usually when they become old, will change permanently into animals of a different kind.

Among Nage, these transformations partly comprise metamorphoses recognized by professional zoologists, including tadpoles changing into frogs and caterpillars into butterflies. However, Nage treat members of such pairs not as immature and mature specimens of a single kind but as distinct kinds (that is, different folk generics). With other animals, including mammals, birds (actually bats), several kinds of snakes, and eels (a particular kind of eel considered a transformation from Russell's vipers), the belief reflects morphological and behavioral similarities, recognized by Nage themselves, between zoological source and product. With these animals, rather than complete metamorphosis, there is a noticeable continuity between the two creatures. In other cases, the transformation is explained instead by situational connections, also recognized by local people, between the two creatures, as for example the idea that tiny bats (Microchiropterans) develop from large grubs found inside bamboo internodes that the bats themselves occupy, after entering through cracks.

A comparable observation applies to turtles and scrubfowl insofar as some of the creatures claimed to hatch from their eggs can be found in proximity to scrubfowl nest mounds and buried clutches of turtle eggs. As demonstrated, however, in these instances the beliefs are more fully accounted for by local observation of the egg-laying habit of the mother animal and the lack of care given to their young, and specifically those young that maintain the same form as the parents. Expressed another way, the discontinuity in the parent-infant relationship is consistent with the idea that some of the young will be creatures of a different kind, i.e., physically and especially morphologically discontinuous with the parents. Again, it is this discontinuity that informs symbolic uses of scrubfowl and turtles-solely as metaphors advertising against poor maternal behavior among human females in the first case and as magical agents in the second.

In this respect it is significant that a comprehensive study of Nage animal metaphors (Forth, 2019a) reveals that animals involved in other reputed transformations (such as grubs into bats, or tadpoles into frogs) do not serve as vehicles of Nage verbal metaphors, nor do Nage employ any of these creatures, actually or nominally, in ritual performances. Ideas about scrubfowl might appear to contravert this generalization. But in fact they do not, for the bird's value as a Nage metaphor of human behavior is exclusively informed by their habit of laying eggs and then deserting them, not by the idea that some of these eggs might hatch as animals of a different kind-itself a belief (as opposed to a metaphor) grounded in the same egg-laying behavior. Much the same goes for marine turtles. Among the Lio, the more prominent part played by this creature's production of strange offspring motivates ritual activity, not any metaphorical reference to humans. And though in one ritual context the name of the turtle is metaphorically applied to cockatoos and parrots, this too is a usage not found in Nage but only 
in Lio, where the scrubfowl metaphor appears to be absent.

As regards animal metaphors and metamorphosis, it is finally worth remarking how, other than birds, most animals Nage regard as laying eggs-including insects, fish, amphibians, and some reptiles (vipers are correctly regarded as bearing young live) - are not observed to brood these. Additionally, some of these egg-layers figure in Nage transformation beliefs (2016:278). Like turtles, these animals too do not serve as vehicles of metaphors for negligent human parents, whereas scrubfowl do. If either scrubfowl or sea turtles appear to participate in a transformation of some sort, the transformation does not involve direct metaphorphosis from a hatched offspring in the way Nage conceive of bats developing directly from grubs or frogs from tadpoles, and moreover from individuals they represent as already mature. Rather, the creature of a different kind emerges from an egg, in the same way young cuckoos are believed to hatch from crow's eggs-another Nage idea, based on a partly mistaken interpretation of brood parasitism. Elsewhere (Forth 2016:280-281) I have distinguished the Nage belief about cuckoos and crows from animal transformation on the grounds that they conceive of cuckoos as offspring of crows and not as metamorphoses from either crows or their eggs. The same applies to the strange offspring of turtles and scrubfowl, whose peculiar character is explained by the equally peculiar, and discontinuous, way the maternal parent lays and subsequently abandons its eggs.

\section{Declarations}

Permissions: None declared.

Sources of funding: None declared.

Conflicts of Interest: None declared.

\section{References Cited}

Berlin, B. 1992. Ethnobiological Classification: Principles of Categorization of Plants and Animals in Traditional Societies. Princeton University Press, Princeton, N.J.

Forth, G. 2010. What's in a Bird's Name: Relationships among Ethno-ornithological Terms in Nage and Other Malayo-Polynesian Languages. In Ethno-ornithology: Birds, Indigenous Peoples, Culture, and Society, edited by S. Tidemann and A. Gosler, pp. 223-237. Earthscan, London.
Forth, G. 2016. Why the Porcupine is not a Bird: Explorations in the Folk Zoology of an Eastern Indonesian People. University of Toronto Press, Toronto.

Forth, G. 2017. Ethnographic Reports of Freshwater Turtles on Flores Island: The Possibilities of an Undocumented Chelonian Species. Herpetological Review 48:304-310.

Forth, G. 2019a. A Dog Pissing at the Edge of a Path: Animal Metaphors in an Eastern Indonesian Society. McGill-Queens University Press, Montreal.

Forth, G. 2019b. Ethnographic Evidence for the Presence of the Coconut Crab Birgus latro (Linnaeus, 1767) (Anomura, Coenobitidae) on Flores Island, Indonesia. Crustaceana 92:921-941. DOI:10.1163/15685403-00003912.

Jones, D. N., R. W. R. J. Dekker, and C. S. Roselaar. 1995. The Megapodes. Oxford University Press, Oxford.

Leseberg, N., and I. Campbell. 2015. Birds and Animals of Australia's Top End: Darwin, Kakadu, Katherine, and Kununarra. Princeton University Press, Princeton, NJ.

Lincoln, G. A. 1974. Predation of Incubator Birds (Megapodius freycinet) by Komodo dragons (Varanus komodoensis). Journal of Zoology 174:419-428.

MacKinnon, J. 1991. Field Guide to the Birds of Java and Bali. Gajah Madah University Press, Yogyakarta, Indonesia.

Simpson, K., and M. Day. 1993. Field Guide to the Birds of Australia, 3rd edition. Viking O'Neill, Ringwood, Australia.

Wallace, A. R. 1922. The Malay Archipelago: The Land of the Orang-utan and the Bird of Paradise. Macmillan, London. 